\title{
Melatonin potentiates "inside-out" nano- thermotherapy in human breast cancer cells: a potential cancer target multimodality treatment based on melatonin-loaded nanocomposite particles
}

This article was published in the following Dove Press journal:

International Journal of Nanomedicine

II October 2017

Number of times this article has been viewed

\author{
Wensheng Xie ${ }^{1,2}$ \\ Qin Gao ${ }^{1,2}$ \\ Dan Wang ${ }^{1,2}$ \\ Wei Wang ${ }^{1,2}$ \\ Jie Yuan ${ }^{1,2}$ \\ Zhenhu Guo 3 \\ Hao Yan ${ }^{1,2}$ \\ Xiumei Wang ${ }^{1,2}$ \\ Xiaodan Sun ${ }^{1,2}$ \\ Lingyun Zhao ${ }^{1,2}$ \\ 'State key Laboratory of $\mathrm{New}$ \\ Ceramics and Fine Processing, School \\ of Materials Science and Engineering, \\ Tsinghua University, ${ }^{2}$ Key Laboratory \\ of Advanced Materials, Ministry \\ of Education of China, School of \\ Materials Science \& Engineering, \\ Tsinghua University, ${ }^{3}$ School of \\ Earth Science and Resources, China \\ University of Geosciences, Beijing, \\ China
}

Correspondence: Xiaodan Sun; Lingyun Zhao

Room 820, Building of Yifu Technology and Science, Tsinghua University,

Beijing, 100084, China

Tel/fax +86 I0 62772325

Email sunxiaodan@mail.tsinghua.edu.cn; lyzhao@mail.tsinghua.edu.cn
Purpose: With the wide recognition of oncostatic effect of melatonin, the current study proposes a potential breast cancer target multimodality treatment based on melatonin-loaded magnetic nanocomposite particles (Melatonin-MNPs).

Methods: Melatonin-MNPs were fabricated by the single emulsion solvent extraction/ evaporation method.

Results: Based on the facilitated transport of melatonin by the GLUT overexpressed on the cell membrane, such Melatonin-MNPs can be more favorably uptaken by MCF-7 cells compared with the melatonin-free nanocomposite particles, which indicates the cancer targeting ability of melatonin molecule. Inductive heating can be generated by exposure to the Melatonin-MNPs internalized within cancer cells under alternative magnetic field, so as to achieve the "inside-out" magnetic nano-thermotherapy. In addition to demonstrating the superior cytotoxic effect of such nano-thermotherapy over the conventional exogenous heating by metal bath, more importantly, the sustainable release of melatonin from the Melatonin-MNPs can be greatly promoted upon responsive to the magnetic heating. The multimodality treatment based on Melatonin-MNPs can lead to more significant decrease in cell viability than any single treatment, suggesting the potentiated effect of melatonin on the cytotoxic response to nano-thermotherapy.

Conclusion: This study is the first to fabricate the precisely engineered melatonin-loaded multifunctional nanocomposite particles and demonstrate the potential in breast cancer target multimodality treatment.

Keywords: melatonin, magnetic nano-thermotherapy, multifunctional nanoparticles, breast cancer, cancer multimodality treatment, cancer target

\section{Introduction}

Ever since first discovered by AB Lerner in 1958, N-acotyl-5-mothoxytryptamine (melatonin), an ancient molecule known as the gatekeeper of circadian clocks, has received overpowering attention in science, medicine and also social media. ${ }^{1-4}$ In the past 2 decades, except for numerous highly cited reviews and technical papers on melatonin published, significantly, it is worth noting that 2 bibliometrics studies on this molecule have been published in 1996 and 2016, suggesting that melatonin is expected to gain even more attention within the near future. ${ }^{5,6}$ It has been widely accepted that melatonin displays an important role in various biological functions and a compelling 
body of evidence has outlined the relevant performances of melatonin to human physiology and pathology. ${ }^{7-9}$ Except for the involvement in so many physiological functions, the anticancer effect of melatonin has been recognized based on the in vitro, in vivo and the clinical data. ${ }^{10-12}$ For example, Kubatka et al has reported that melatonin significantly decreased tumor volume in rats by $67 \%$ compared with untreated controls in chemically induced mammary carcinoma model. ${ }^{13}$ Moreover, melatonin also has been shown to enhance the efficiency of chemotherapeutic compounds, tumor necrosis factor-related apoptosis-inducing ligand, photodynamic therapy, ionizing radiation and hyperthermia (melatonin and hyperthermia)..$^{14,15}$

Among various types of cancer cells which demonstrate anti-cancer effect under the melatonin treatment, breast cancer cells have attracted great attention and is, so far, one of the most widely studied cell lines. Breast cancer is one of the most frequently occurring cancers, and one of the leading causes of death among women aged $40-55$ years. ${ }^{16}$ For breast cancer treatment, though a certain degree of success has been achieved by the current modalities, including chemotherapy, radiotherapy, hyperthermia (or thermotherapy), gene therapy or biotherapy, ${ }^{17-21}$ etc, the single-mode treatment is by far the optimal strategy for cancer treatment due to dose limitation or the resistance of cancer cells to specific modality. A rational combination of the aforementioned protocols (for instance, chemotherapy combined with radiotherapy, or biotherapy combined with hyperthermia, etc) has been investigated for the enhancements or synergistic effects that may significantly improve the therapeutic effect and reduce the side effect in the meanwhile. ${ }^{22,23}$ Recently, nanoparticles (NPs) for therapeutic carriers have aroused continuous interest as the particles in nanoscale normally possess high surface area and enable sophisticated functionalization with different therapeutic agents, thus to achieve the multifunctions within one nanoplatform. ${ }^{24}$ In particular, such precisely engineered multifunctional NPs can simultaneously target cancer cells, enable the location of therapeutic agents and consequently release drugs triggered by an external stimulus. ${ }^{25}$ Though the actions of melatonin on cancer target potential and anticancer effect (both oncostatic effect and efficiency enhancement when combined with other modalities) have been confirmed, so far to the best of our knowledge, little attention has been paid on melatonin-based multifunctional NPs formulation for cancer target multimodality treatment. As the first trial, our work provided a proof-of-concept study to demonstrate the successful fabrication of melatonin-based multifunctional nanoplatform and its potential in cancer target multimodality treatment.
In the current study, poly(lactic-co-glycolic acid) (PLGA), owing to its excellent biocompatibility and biodegradability, was employed as the matrix for the fabrication of nanocarriers within which both the magnetic NPs (MNPs) and melatonin can be incorporated. Such nano-therapeutic agents can realize the sustainable release of melatonin. Besides, upon exposure to the alternative magnetic field (AMF), inductive heat can be generated through Neel relaxation or Brownian movement mediated by the MNPs. While the heat can directly kill the cancer cells, more importantly, it can also promote or facilitate the drug release and possible synergistic effect can be achieved between hyperthermia and melatonin. Another significance of the multifunctional nanoplatform is that the target ability of melatonin can be depicted as our results demonstrated that compared with blank PLGA NPs, more cellular internalization can be achieved by the melatonin-loaded PLGA NPs. Our results suggest the great potential of magnetic melatonin nano-therapeutic agents as multifunctional devices for target multimodality treatment of human breast cancer.

\section{Materials and methods Main agents}

Melatonin ( $>98.0 \%$ purity) was supplied by Tokyo Chemical Industry (TCI, Tokyo, Japan). Iron (III) acetylacetonate (Fe[acac $]_{3}$ ), polyvinyl alcohol (PVA, 87\%-90\% hydrolyzed, wt. 30,000-70,000) and PBS (pH 7.4) were purchased from Sigma-Aldrich (St Louis, MO, USA). Methylbenzene, oleylamine, and dichloromethane (DCM) were obtained from Sinopharm Group Co., Ltd. (Beijing, China). PLGA (50:50, wt. 90,000) was purchased from Jinan Daigang Biomaterial Co., Ltd. (Shangdong, China). High-glucose DMEM (H-DMEM), Roswell Park Memorial Institute 1640 medium (RPMI 1640), fetal bovine serum (FBS), penicillin-streptomycin (PS), trypsin-EDTA $(0.25 \%)$ were purchased from Gibco (Life Technologies, Carlsbad, CA, USA). Cell Counting Kit-8 (CCK-8 assay) were obtained from Dojindo Molecular Technologies Inc. (Kumamoto, Japan). Rhodamine phalloidin and Coumarin-6 were supplied by Melone Pharmaceutical Co., Ltd. (Dalian, China). Deionized (DI) water was used throughout the study. All other chemicals and reagents were of analytical grade from commercial sources.

\section{Synthesis of iron oxide MNPs as magnetic hyperthermia agents}

Iron oxide $\left(\mathrm{Fe}_{3} \mathrm{O}_{4}\right)$ MNPs (IO-MNPs) were synthesized through the thermal decomposition method as reported previously by Sun et al. ${ }^{26}$ In a typical synthesis process, $\mathrm{Fe}(\mathrm{acac})_{3}$ 
was employed as precursor with toluene as reaction medium, and oleylamine as both surfactant and reducing agent. Briefly, $\mathrm{Fe}(\mathrm{acac})_{3}(1 \mathrm{mmol})$ was dissolved in $20 \mathrm{~mL}$ of methylbenzene and $5 \mathrm{~mL}$ oleylamine under mild stirring. The red solution was then transferred into a Teflon-liner stainless-steel autoclave (40 $\mathrm{mL}$ in total capacity) and kept at $180^{\circ} \mathrm{C}$ for $12 \mathrm{~h}$. After natural cooling, the product was precipitated and washed with ethanol and hexane alternatively for 3 times. The final product was dispersed in hexane for further use.

\section{Fabrication of melatonin-loaded magnetic nanocomposite particles (Melatonin- MNPs)}

Melatonin-MNPs were fabricated by the single emulsion solvent extraction/evaporation method as described in our previous publication. ${ }^{27}$ Briefly, $110 \mathrm{mg}$ PLGA, $10 \mathrm{mg}$ melatonin and $30 \mathrm{mg}$ the as-synthesized IO-MNPs were mixed with $8 \mathrm{~mL}$ DCM. The mixture was magnetically stirred until both PLGA and melatonin completely dissolved while IO-MNPs homogenously dispersed within the DCM. The suspension was added dropwise into $120 \mathrm{~mL}$ aqueous phase with PVA $(5 \%, w / w)$ as surfactant. The mixture was then emulsified by probe sonicator with $300 \mathrm{~W}$ in pulse mode for $180 \mathrm{~s}$. The formed oil-in-water emulsion was then stirred overnight at room temperature for the complete evaporation of DCM. Same protocol was applied to prepare the melatonin-free MNPs (without adding melatonin) and melatonin-loaded PLGA NPs (without adding IO-MNPs). The polymer solution can also contain $0.05 \%$ (w/v) coumarin-6 as fluorescent marker probe for the cellular uptake observation. The various kinds of resultant particles were harvested by centrifugation at 12,000 rpm for $10 \mathrm{~min}$ and washed 3 times with DI water.

\section{Characterizations of Melatonin-MNPs}

Surface morphology of IO-MNPs, melatonin-loaded PLGA NPs and Melatonin-MNPs was imaged by the scanning electronic microscopy (SEM, S-4800, Hitachi, Tokyo, Japan) at an accelerating voltage of $10 \mathrm{kV}$. Samples were coated with platinum by high-resolution ion beam coater (Gatan, model 681, München, Germany) for $300 \mathrm{~s}$ at 4.2 TORR before loading into the instrument chamber. The shape and surface morphology of the aforementioned 3 types of particles were also investigated by transmission electronic microscopy (TEM, HT7700, Hitachi), in which the suspensions of the particle samples were dropped onto the surface of copper grid with carbon film and dried at room temperature. Size and size distribution of the as-prepared particles were measured by the dynamic light scattering (NANOPHOX). The samples were prepared by diluting the particle suspension with DI water to a count rate of $300 \mathrm{kcps}$ and sonicated for $5 \mathrm{~min}$ before the measurement. The mass ratio of IO-MNPs loading within the Melatonin-MNPs was analyzed with thermal gravimetric analysis (TGA, Q5000 IR) from room temperature to $600^{\circ} \mathrm{C}$ at the atmosphere of air.

\section{Magnetic and inductive heating properties of Melatonin-MNPs}

The magnetic properties of both IO-MNPs and MelatoninMNPs were measured by vibrating sample magnetometer (VSM730T). Induced heating properties of the IO-MNPs and Melatonin-MNPs were performed by exposing the suspensions of various particle concentrations under the AMF of $282 \mathrm{kHz}, 9.3 \mathrm{kA} / \mathrm{m}$ generated by inductive heating device (Shuangping Instrument Technology, Co., Ltd., Shenzhen, China). Optical fiber probe (ThermAgile-RD; Xi'an Heqi Opto-Electronic Technology Co., Ltd., Shaanxi, China) was applied for the real-time temperature measurement. The probe fibers were connected to a 4-channel millivoltmeter and the data were collected every $2 \mathrm{~s}$.

\section{Loading ratio (LR), encapsulation efficiency (EE) of melatonin and in vitro release}

The LR and EE of melatonin within the Melatonin-MNPs were calculated by the following equations:

$$
\begin{gathered}
\mathrm{LR}(\%)=\frac{\mathrm{W}_{\text {Melatonin }}}{\mathrm{W}_{\text {Melatonin }}+\mathrm{W}_{\text {IO-MNPs }}+\mathrm{W}_{\text {PLGA }}} \times 100 \% \\
\mathrm{EE}(\%)=\frac{\mathrm{W}_{\text {Melatonin entrapped within the Melatonin-MNPs }}}{\mathrm{W}_{\text {Melatonin during the Melatonin-MNPs fabrication }}} \times 100 \%
\end{gathered}
$$

The LR and EE of melatonin within the Melatonin-MNPs and in vitro release were determined by high-performance liquid chromatography (HPLC, 1290 Infinity Binary Pump, Agilent, Santa Clara, CA, USA). A reverse-phase Eclipse XDB-C18 column $(250 \times 4.6 \mathrm{~mm}$, pore size $5 \mu \mathrm{m}$, Agilent Technologies) was used. $10 \mathrm{mg}$ Melatonin-MNPs was dissolved in $1 \mathrm{~mL}$ DCM, and $5 \mathrm{~mL}$ mobile phase (acetonitrilewater, 55:45) was added to extract melatonin. A flowing nitrogen atmosphere was introduced to evaporate the DCM until a clear solution was obtained. The solution was then put into HPLC vial and a $20-\mu \mathrm{L}$ aliquot of the sample was injected into the HPLC system. Mobile phase was delivered at a flow rate of $1.0 \mathrm{~mL} / \mathrm{min}$ and the column efficient was detected at $222 \mathrm{~nm}$ with an ultraviolet detector. 
The in vitro release of melatonin from the Melatonin-MNPs was measured in triplicate in PBS (pH 7.4). Melatonin-MNPs $10 \mathrm{mg}$ was suspended in $10 \mathrm{~mL}$ buffer solution in centrifuge tube. Then, the tubes were placed in an orbital shaking bath, which were maintained at $37^{\circ} \mathrm{C}$ and shaken horizontally at $50 \mathrm{rpm}$. At designated time intervals, the tubes were taken out of the water bath and centrifuged at 12,000 rpm for $10 \mathrm{~min}$. The precipitated Melatonin-MNPs were resuspended in $10 \mathrm{~mL}$ of fresh buffer before being put back in the shaker bath. The supernatant was taken for analysis of melatonin concentration, which was extracted with $1 \mathrm{~mL}$ of DCM and followed by adding $3 \mathrm{~mL}$ of the mobile phase as aforementioned, then evaporated until a clear solution was obtained under a stream of nitrogen. HPLC analysis was then conducted as previously described. To study the effect of heat stimulus on the drug release, samples were exposed under the AMF for 20 min before the extraction of the melatonin.

\section{Cell culture and cellular uptake of Melatonin-MNPs}

MCF-7 human breast cancer cells (acquired from ATCC) were routinely cultured with H-DMEM supplemented with $10 \%$ FBS and $1 \%$ PS solution at $37^{\circ} \mathrm{C}$ with $5 \% \mathrm{CO}_{2}$ atmosphere. Cells were seeded in 6-well plate at a density of $10^{4}$ cells/well and co-incubated with $100 \mu \mathrm{g} / \mathrm{mL}$ coumarin-6-loaded Melatonin-MNPs or melatonin-free MNPs for 1, 2, 4 and $8 \mathrm{~h}$. Following the removal of the particle containing medium, the cell monolayers were rinsed 3 times with cold PBS to remove the excess particles that were not taken up by the cells. Then, cells were fixed with $4 \%$ paraformaldehyde for $30 \mathrm{~min}$, washed with PBS for 3 times and stained by $1.5 \mathrm{~mL}$ rhodamine phalloidin $(50 \mu \mathrm{g} / \mathrm{mL})$ for $15 \mathrm{~min}$. Finally, cells were washed again to remove the remaining rhodamine phalloidin. The cells were viewed and imaged by using a confocal laser scanning microscope (CLSM, Zeiss LSM 780, Carl Zeiss Meditec AG, Jena, Germany) equipped with the Fluoview FV300 imaging software. Fluorescein isothiocyanate filter was selected to get images for coumarin-6-loaded NPs and rhodamin phalloidinstained cytoskeleton. The average fluorescence intensity of NPs was calculated using the histo mode of CLSM.

\section{Exposure to metal bath heating and magnetic hyperthermia}

MCF-7 cells in the exponential phase seeded in 96-well plate were subjected to heating treatment and 2 heating modes were applied in the current investigation. Cells were divided into 4 groups: the negative control group in which cells were routinely cultured (group A); the metal bath heating group (group B); the magnetic hyperthermia group (group C); and the positive control group where cells were exposed under AMF (group D). For the metal bath heating (group B), cells were heated at $37^{\circ} \mathrm{C}, 40^{\circ} \mathrm{C}, 43^{\circ} \mathrm{C}, 46^{\circ} \mathrm{C}, 50^{\circ} \mathrm{C}$ for $20 \mathrm{~min}$ on the metal bath (Dry Bath Incubator, DH300; Hangzhou Ruicheng Instrument Co., Ltd., Zhejiang, China). Under the mode of magnetic hyperthermia, cells were co-incubated with melatonin-free MNPs and then subjected to AMF. Upon heating treatment, the field intensity of the AMF was carefully adjusted to obtain the desired hyperthermic temperatures which was same with the temperature of group B. For both heating modes, the temperature was monitored by the optical fiber probe as aforedescribed. In order to elucidate the effect of AMF exposure on the cytotoxicity of MCF-7 cells, a positive control group (group D) was set for cell AMF exposure only. Routinely cultured cells were exposed under the same condition as the cells subjected to magnetic hyperthermia. The cells were incubated for another $2 \mathrm{~h}$ before viability analysis by CCK- 8 assay, the absorbance of which was determined at 450 $\mathrm{nm}$ by spectrophotometry of a microplate reader (Varioskan LUX; Thermo Fisher Scientific Inc., Waltham, MA, USA).

\section{In vitro cytotoxicity of melatonin treatment}

To test the in vitro cytotoxicity of melatonin treatment, melatonin solution in H-DMEM medium of various concentrations $(5.000,1.000,0.500,0.100,0.050,0.010,0.005$, $0.001,0 \mu \mathrm{g} / \mathrm{mL}$ ) were prepared first. Then MCF-7 cells in the exponential phase were detached, counted and seeded in 96-well plate at a concentration of $1.5 \times 10^{3}$ cells $/ \mathrm{mL}$. After $24 \mathrm{~h}$ incubation, the original medium was sucked out and $200 \mu \mathrm{L}$ melatonin solution was added into each hole for further incubation. The viability of cells was measured by CCK- 8 assay test at 24, 48 and $72 \mathrm{~h}$. And the $50 \%$ inhibitive concentration value $\left(\mathrm{IC}_{50}\right)$ was calculated from polynomial regression analysis by SPSS (IBM7 SPSS Version 23) for windows. ${ }^{28}$

\section{In vitro cytotoxicity of magnetic nano- thermotherapy combined with melatonin mediated by Melatonin-MNPs}

In order to measure the in vitro cytotoxicity of magnetic nano-thermotherapy combined with melatonin mediated by Melatonin-MNPs, MCF-7 cells in the exponential phase seeded in 96-well plate at a concentration of $1.5 \times 10^{3}$ cells $/ \mathrm{mL}$ were divided into 4 groups, namely, control group in which cells were routinely cultured (group A); melatonin treatment group (Group B) in which cells were cultured in the $10 \mu \mathrm{g} / \mathrm{mL}$ 
melatonin containing cultural medium; magnetic hyperthermia group (Group C) in which cells were co-incubated with melatonin-free MNPs containing cultural medium and bimode treatment group (Group D, magnetic hyperthermia combined with melatonin treatment) in which cells were cultured in the medium with Melatonin-MNPs. Cells in Groups $\mathrm{C}$ and $\mathrm{D}$ were exposed under AMF for magnetic heating mediated by the particles inside the medium, the so-called "inside-out" hyperthermia. After heating, the cells were incubated for another $2 \mathrm{~h}$ before viability assay by CCK-8 assay test as previously described.

\section{Statistical analysis}

All data were presented as the mean \pm standard error. Statistical analysis was performed using one-way analysis of variance followed by a Newman-Keuls post hoc $t$-test with the SPSS (IBM7 SPSS Version 23) for windows. $P$-values $<0.05$ were considered statistically significant.

\section{Results}

The schematic illustration for structure of Melatonin-MNPs is shown in Figure 1. PLGA NPs are taken as the matrix to co-incorporate melatonin and IO-MNPs. Figure 2 shows the morphology and size distribution of IO-MNPs, melatoninloaded PLGA NPs and Melatonin-MNPs. IO-MNPs coated with oleic acid and oleylamine have been successfully synthesized by the one-pot thermal decomposition method. The as-synthesized IO-MNPs were highly monodispersed and non-agglomerated (Figure 2A2). The particle size was found to be $15-20 \mathrm{~nm}$, which is in the superparamagnetic size range (Figure 2A3). IO-MNPs synthesized by the decomposition method were hydrophobic as they could be homogeneously dispersed in hexane (insertion in Figure 2A2) and kept stable for at least 1 month. The super-hydrophobic property of IO-MNPs is favorable for the fabrication of Melatonin-MNPs by the single emulsion method, as the IO-MNPs could be readily and stably dispersed in organic phase with PLGA. As revealed by Figure 2C2, IO-MNPs are homogenously dispersed within the PLGA matrix. By comparing the SEM and TEM images of melatonin-loaded PLGA NPs and Melatonin-MNPs, it can be noticed that both particles are with regular spherical shape and smooth surface without any noticeable pinholes, tiny pores or cracks (Figure 2B1 and $\mathrm{C} 1$ ), indicating that the incorporation of IO-MNPs would not interfere the formation or the surface morphology of the PLGA NPs. Figure $2 \mathrm{C} 1$ also demonstrates that no free IO-MNPs could be observed on the surface of particles. Such phenomenon can also be attributed to the super-hydrophobicity of the IO-MNPs so that the IO-MNPs would rather stay inside the inner part of polymer matrix but not on the surface. More importantly, the encapsulation of the IO-MNPs would result in almost unnoticeable size change as compared with that of the melatonin-loaded PLGA NPs. It can be seen that both the IO-MNPs and melatonin-loaded PLGA NPs have very similar size (200 250 nm) and size distribution (Figure 2B3 and C3). Particle size is a key factor in the cellular uptake, as will be discussed later.

It was difficult to quantify the mass ratio of IO-MNPs loading within the Melatonin-MNPs solely based on the TEM images, hence the TGA analysis was performed. The weight loss below $200^{\circ} \mathrm{C}$, as illustrated in Figure $3 \mathrm{~A}$, which is attributed to the evaporation of absorbed water, is

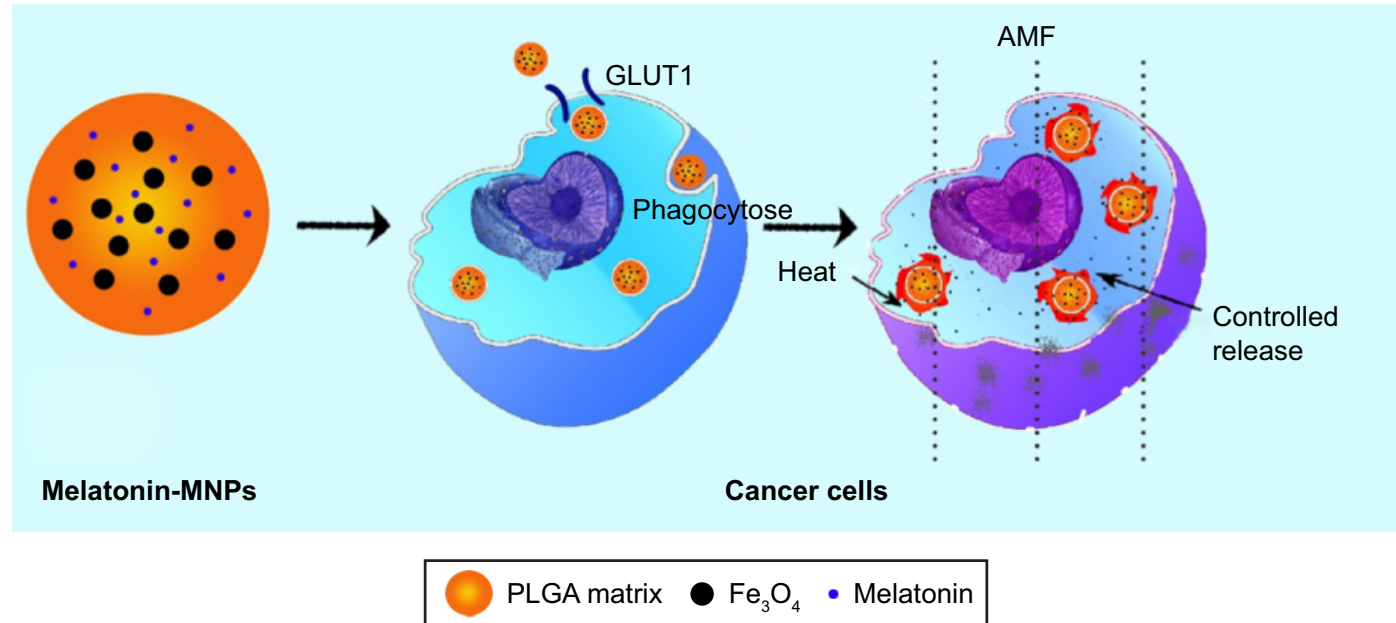

Figure I Schematic illustration of the structure of Melatonin-MNPs and the treatment process of cancer in vitro using Melatonin-MNPs. Abbreviations: AMF, alternative magnetic field; MNPs, magnetic nanocomposite particles; PLGA, poly (lactic-co-glycolic acid). 

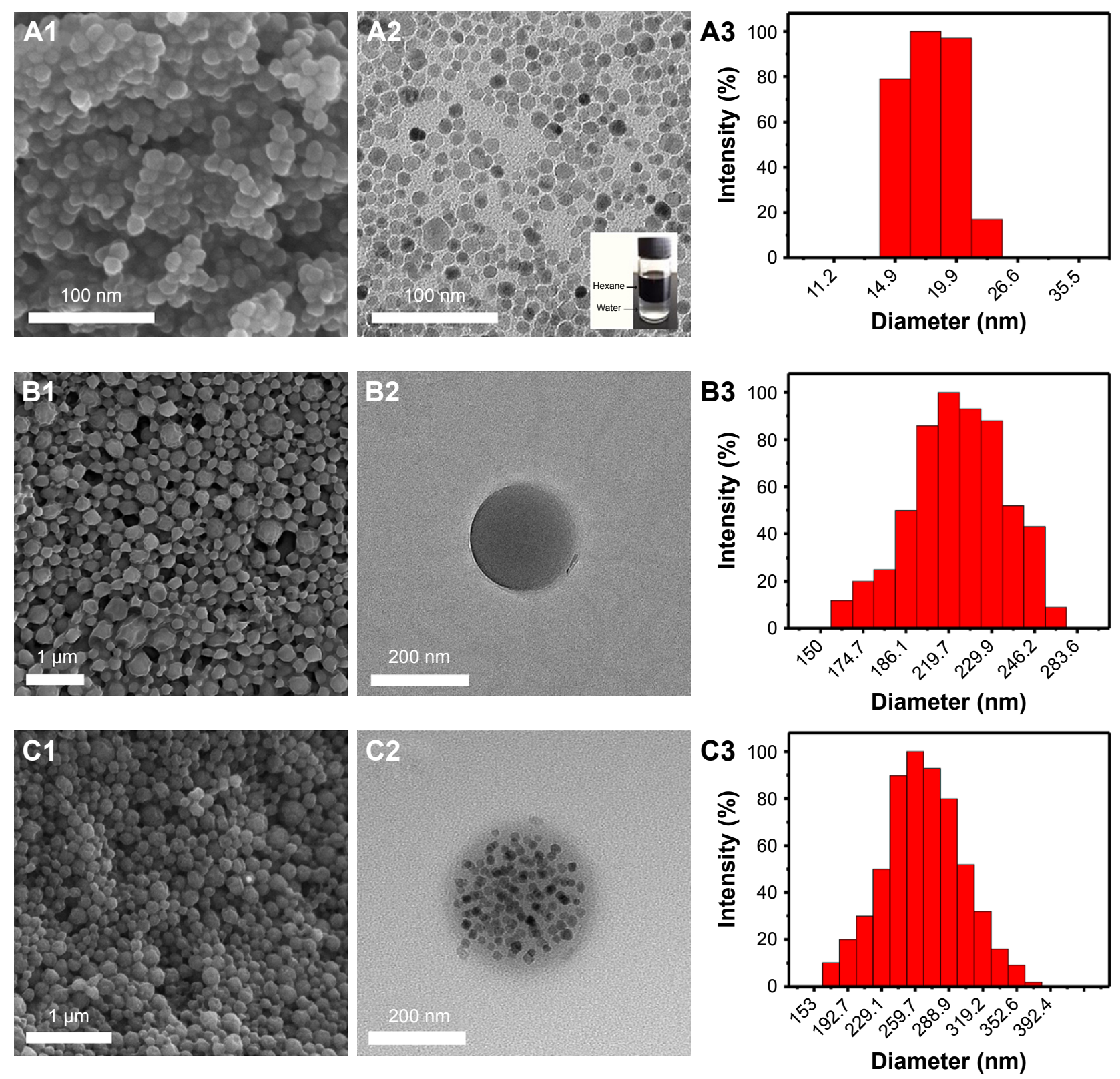

Figure 2 Scanning electronic microscopy and transmission electronic microscopy images of $\mathrm{Fe}_{3} \mathrm{O}_{4}$ magnetic NPs (AI, A2), PLGA NPs (BI, B2), and Melatonin-MNPs (CI, C2). A3, B3 and C3 are the DLS graphs of $\mathrm{Fe}_{3} \mathrm{O}_{4}$ magnetic NPs, PLGA NPs and Melatonin-MNPs, respectively.

Abbreviations: DLS, dynamic light scattering; MNPs, magnetic nanocomposite particles; NPs, nanoparticles; PLGA, poly (lactic-co-glycolic acid).

negligible for both Melatonin-MNPs and melatonin-loaded PLGA NPs. Weight loss at $200^{\circ} \mathrm{C} \sim 500^{\circ} \mathrm{C}$ may account for the mass loss of polymer. The difference in weight loss between these 2 particles was shown to be about $8 \%$, which can be attributed to the load of IO-MNPs within the Melatonin-MNPs. The magnetic properties of IO-MNPs and Melatonin-MNPs were evaluated by field-dependent magnetization M-H measurements at $300 \mathrm{~K}$ using a VSM. As shown in Figure 3B, both Melatonin-MNPs and IO-MNPs show superparamagnetic behaviors for neither coercivity nor remanence were observed. The saturation magnetization
(Ms) of the IO-MNPs was determined to be $55.04 \mathrm{emu} / \mathrm{g}$. After emulsion within the PLGA matrix, though the superparamagnetic nature of IO-MNPs was not affected, Ms was observed to drop down to $11.31 \mathrm{emu} / \mathrm{g}$. Such decreased Ms was attributed to the decreased effective weight fraction of the magnetic core within the Melatonin-MNPs.

The inductive heating property of the as-prepared particles was studied in order to evaluate their potential as mediators for magnetic hyperthermia. IO-MNPs suspended in hexane and Melatonin-MNPs suspended in PBS with various particle concentrations were exposed under 
A

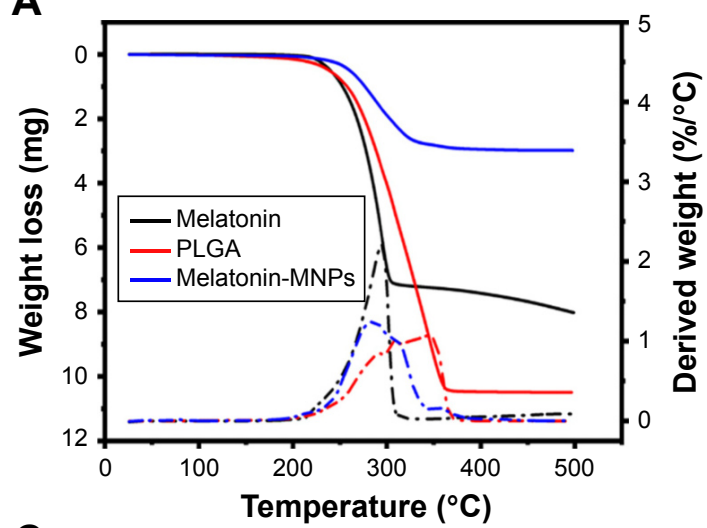

C

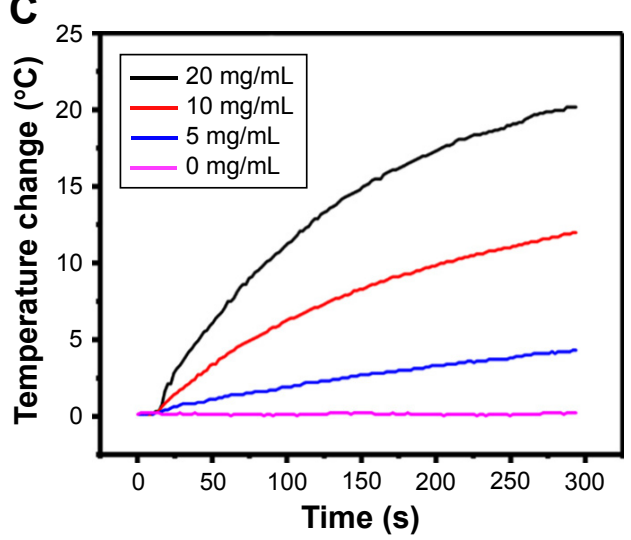

B

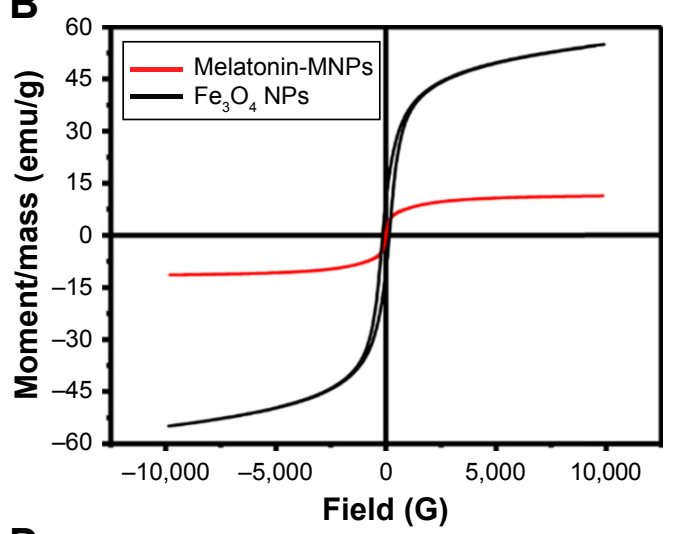

D

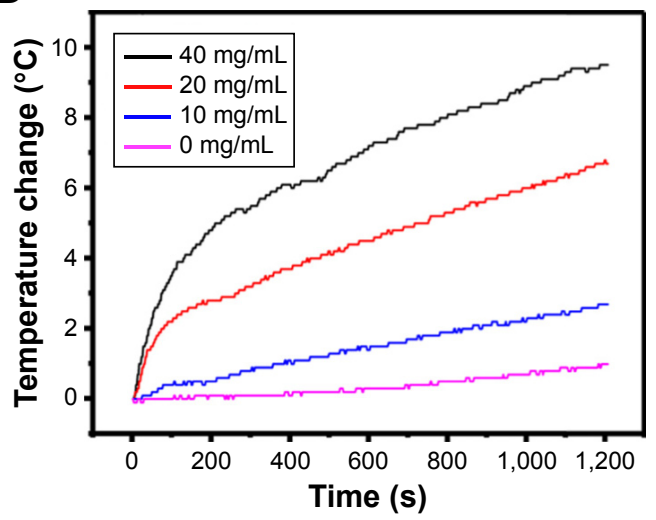

Figure 3 (A) TGA curves for melatonin, PLGA and Melatonin-MNPs. (B) Hysteresis curve of original $\mathrm{Fe}_{3} \mathrm{O}_{4} \mathrm{NPs}$ and Melatonin-MNPs. Hyperthermia study showing the time-dependent temperature rise of $\mathrm{Fe}_{3} \mathrm{O}_{4}(\mathbf{C})$ and Melatonin-MNPs (D) suspensions under a alternative magnetic filed with intensity of $9.3 \mathrm{kA} / \mathrm{m}$ at $282 \mathrm{kHz}$ frequency.

Abbreviations: TGA, thermal gravimetric analysis; MNPs, magnetic nanocomposite particles; NPs, nanoparticles; PLGA, poly (lactic-co-glycolic acid); DI, deionized water.

an AMF and the heating profiles are shown in Figure 3C and D. It was observed that rapid temperature increase can be achieved by AMF exposure and higher particle concentration would result in a greater increase of temperature.

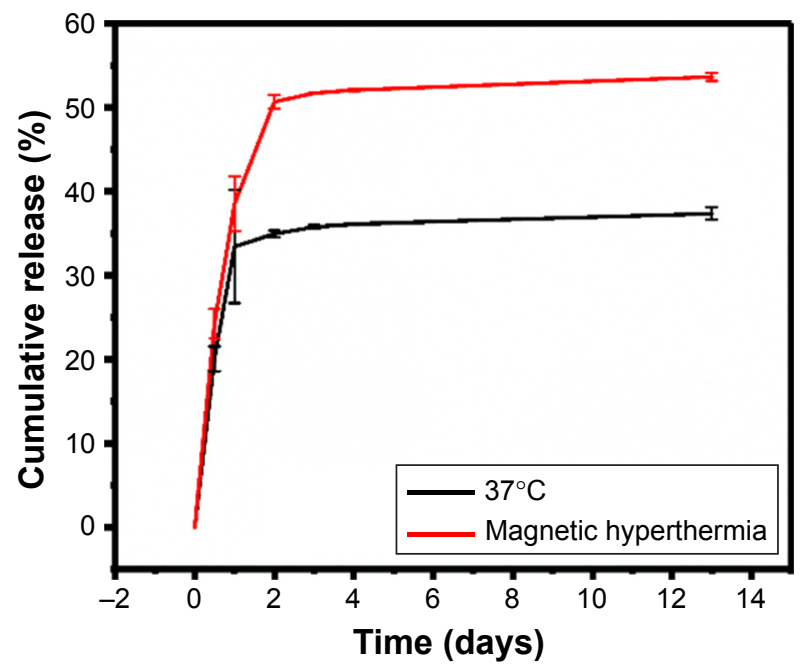

Figure 4 Cumulative release of melatonin from the Melatonin-MNPs under the shaking bath both at $37^{\circ} \mathrm{C}$ and exposed to an alternative magnetic field for 20 mins each day. Abbreviation: MNPs, magnetic nanocomposite particles.
The desired temperature was achieved by appropriately choosing the particle concentration, which guaranteed the temperature requirements for the cancer hyperthermia treatment.

EE and sustainable release of melatonin within the Melatonin-MNPs plays an important role in the delivery formulation and directly affects the therapeutic effect. In the current study, EE and cumulative release of melatonin were evaluated by HPLC assay and a typical chromatogram for melatonin under the current HPLC conditions is presented in Figure 4. LR and EE of melatonin within the particle matrix were calculated to be $0.2 \%$ and $71.7 \%$ based on the fabrication protocol as aforedescribed. The in vitro release profiles were obtained by representing the percentage of released melatonin with respect to the amount of melatonin loaded within Melatonin-MNPs. The accumulative release profiles of melatonin from the Melatonin-MNPs at normal body temperature and heating exposure within 14 days are shown in Figure 4, it can be noticed that there is an initial burst release in the first 2 days, during which period, $37.5 \%$ and $53.5 \%$ of melatonin were released from the 
A

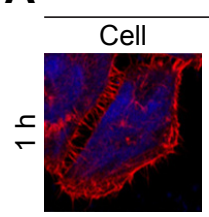

PLGA
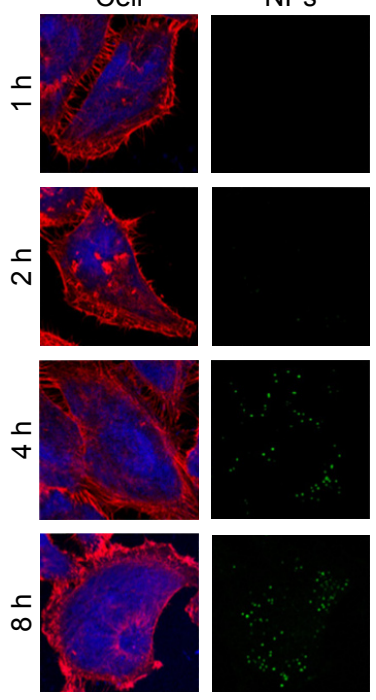
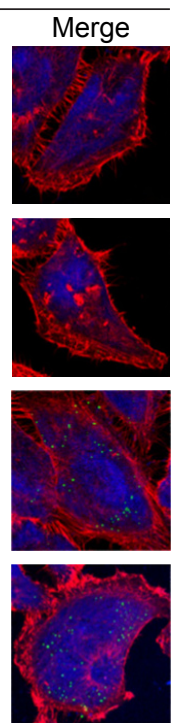

Melatonin/PLGA
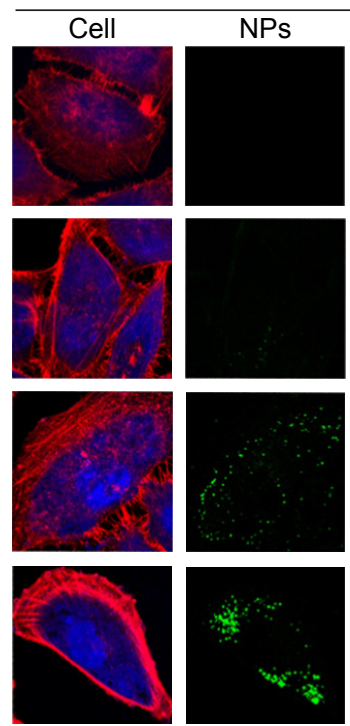

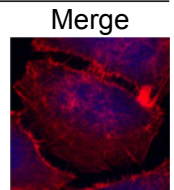

B1

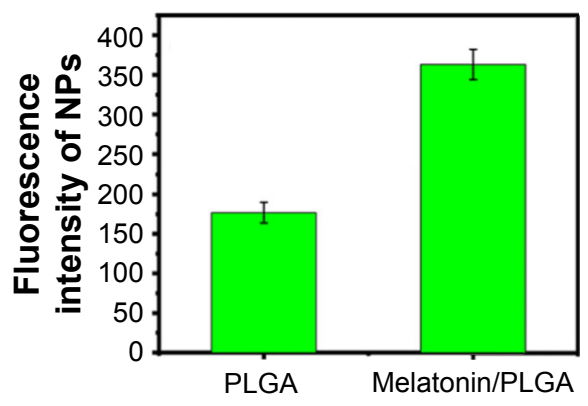

B2

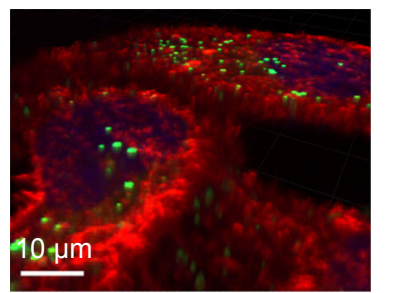

Figure 5 (A) Cellular uptake efficiency of both PLGA and melatonin/PLGA NPs at concentration of $100 \mu g / m L$ in MCF-7 cells. PLGA was designed as the control to examine the targeting effect of melatonin on MCF-7 cell line. The images were taken by laser scanning confocal microscope (LSM780). Cytoskeleton was stained by rhodaminephalloidin (red), the nuclei of cells were stained by DAPI (blue) and coumarin-6 was loaded in Melatonin-MNPs to track the NPs (green). (BI) The fluorescence intensity of NPs (green) after $8 \mathrm{~h}$ incubation with MCF-7 cells; (B2) three-dimensional images from different perspectives of MCF-7 cells using the Z-stack model of laser scanning confocal microscope.

Abbreviations: MNPs, magnetic nanocomposite particles; NPs, nanoparticles; PLGA, poly(lactic-co-glycolic acid).

Melatonin-MNPs at normal body temperature and heating exposure, respectively. In the following days, melatonin was released in a tardy manner. The burst release phenomenon was attributed to the melatonin loaded near the surface of Melatonin-MNPs, and the later sustainable release of melatonin was due to the encapsulation of PLGA. Figure 4 also clearly demonstrates that Melatonin-MNPs can realize the heat-responsive delivery of melatonin by exposing the Melatonin-MNPs to an external AMF, which would greatly facilitate the melatonin release from the vehicles.

The cellular uptake of the PLGA NPs by MCF-7 cells after designated incubation time was qualitatively evaluated using CLSM. Here, we compared the cellular uptake efficiency between the PLGA NPs with or without melatonin incorporation to show that the melatonin-loaded NPs could be more efficiently internalized into the MCF-7 cells. Figure 5A shows the confocal images of MCF-7 cells incubated with the PLGA NPs with or without melatonin incorporation. The green fluorescence represents coumarin-6-loaded NPs, while the red fluorescence represents the cytoskeleton of MCF-7 cells stained by rhodamine phalloidin. It can be observed from those images that coumarin-6-loaded NPs scattering within the rhodamine-phalloidin stained cytoskeleton, suggesting that the NPs have been internalized into the cytoplasm of MCF-7 cells. By comparing the 2 types of confocal images, it could be observed that more green fluorescence NPs appear within the cells incubated with melatonin-loaded PLGA NPs, indicating a higher cellular uptake efficiency of the melatonin-incorporated NPs. It was further confirmed by the fluorescence intensity of NPs (Figure 5B1), which showed that the cellular uptake efficiency of PLGA NPs with melatonin incorporation was 2 times higher than that of PLGA NPs without melatonin incorporation. Such phenomenon is time-dependent; as it can be seen from Figure 5A, longer incubation time would result in stronger green fluorescence intensity. Figure 5B2 shows 3-dimensional analysis of the confocal image of the cells incubated with the fluorescent PLGA NPs, which clearly demonstrates the fluorescent signals inside the cells and not just attached to the cell membrane. The result shows that not only could the melatonin function as a biological therapeutic agent, but also as a targeting ligand to enhance the internalization of the NPs into the MCF-7 cells, as will be discussed later.

In order to demonstrate the unique advantages of Melatonin-MNPs as mediators for multimodality of cancer treatment, first, the effects of hyperthermia treatment of MCF-7 cells by different heating modes (IO-MNPs-mediated magnetic heating or metal bath heating) were compared. It can be noticed from Figure 6A that exposure under the AMF had negligible effects on the cell proliferation, and this suggests that during the process of magnetic heating, AMF has little contribution to the cell proliferation. MCF-7 

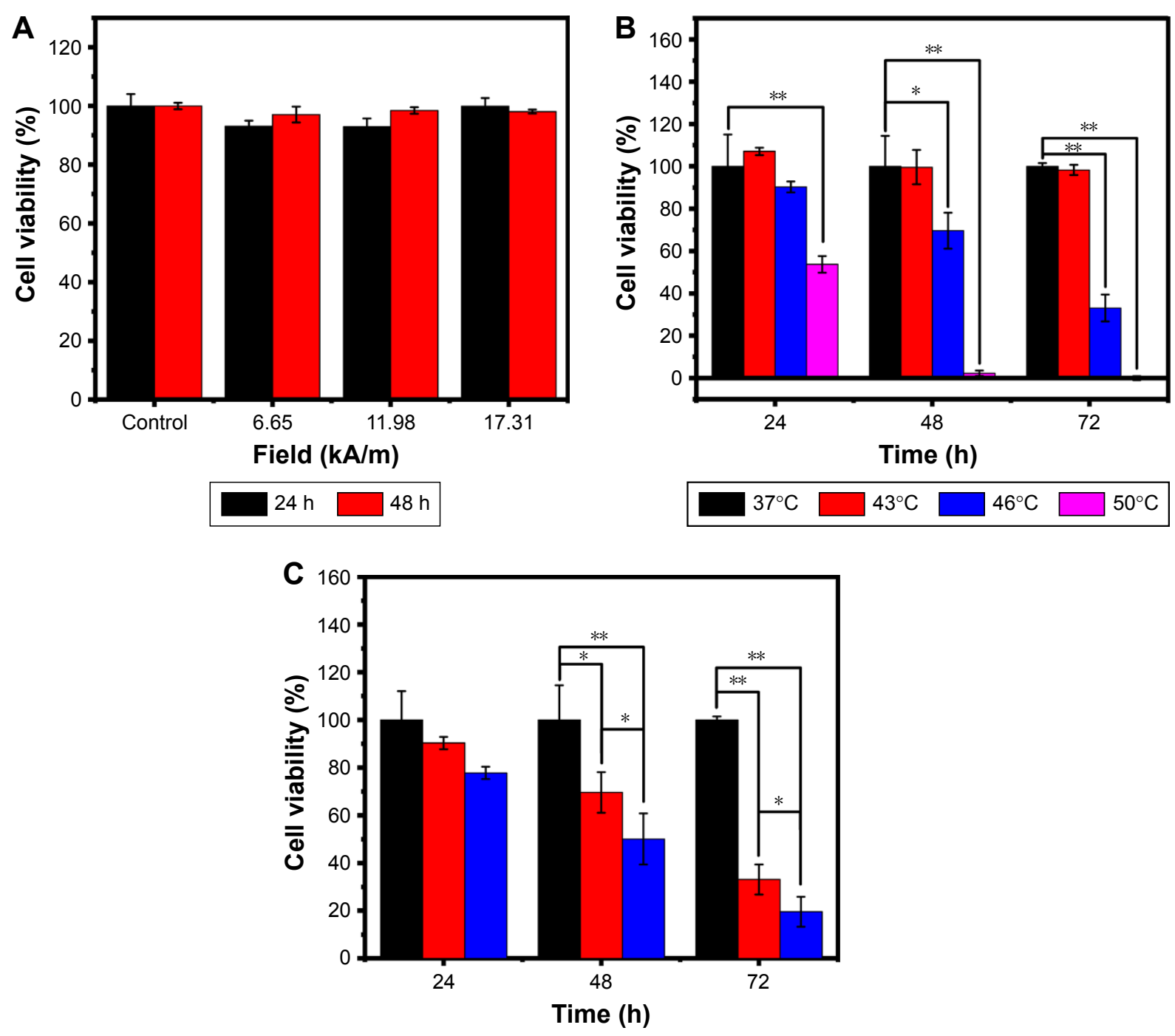

$\square$ Control $\square$ Metal bath $\square$ Magnetic hyperthermia

Figure 6 The viability of the MCF-7 cells after treatment with different conditions. (A) The cell survival after exposure to AMF of different intensities for I0 mins. (B) The cell viabilities after incubation under different temperature surroundings for 20 mins with metal bath every 24 h. (C) The survival of MCF-7 cells after treating with metal bath hyperthermia or magnetic hyperthermia at $46^{\circ} \mathrm{C}$, the control group was incubated at $37^{\circ} \mathrm{C}, \mathrm{n}=6 ; * \mathrm{P}<0.05 ; * * \mathrm{P}<0.00 \mathrm{I}$.

Abbreviation: AMF, alternative magnetic field.

cells are rather heat-resistant by metal-bath heating, as the heating temperature of $43^{\circ} \mathrm{C}$ has very little effect on the viability of cells and such effect is independent of the post-hyperthermia recovery time. It can be noticed that the normalized cell viability keeps around $107.11 \%, 99.64 \%$ or $98.31 \%$ at 24,48 or $72 \mathrm{~h}$ after the heating treatment, respectively (Figure 6B). The inhibitory effect of hyperthermia on the cell viability happens at higher temperature $\left(>46^{\circ} \mathrm{C}\right)$ and such effect is time-dependent, as longer incubation time after the heating treatment would cause more remarkable decrease in the cell viability. The effects of heating modes under the same thermal dose were compared, and the results are shown in Figure 6C. It can be seen that there exist distinguished differences in the cell viability under the same thermal dose $\left(46^{\circ} \mathrm{C}\right.$ for $20 \mathrm{~min}$ ) for both heating modes. Magnetic heating mediated by magnetic nanocomposite PLGA particles would result in a significant decrease of the cell viability with the same thermal dose, and such difference is independent of the post-heating recovery time.

CCK-8 assay was carried out to verify the impact of melatonin on MCF- 7 breast cancer cells after 24, 48 and $72 \mathrm{~h}$ incubation. As shown in Figure 7, the antiproliferation effect of melatonin on MCF-7 cells are concentration-dependent in the range of $1 \mathrm{ng} / \mathrm{mL} \sim 1 \mu \mathrm{g} / \mathrm{mL}$. Generally speaking, lower concentration $(0-10 \mathrm{ng} / \mathrm{mL})$ has little effect on the cell proliferation, and after calculation, the $\mathrm{IC}_{50}$ values for melatonin 


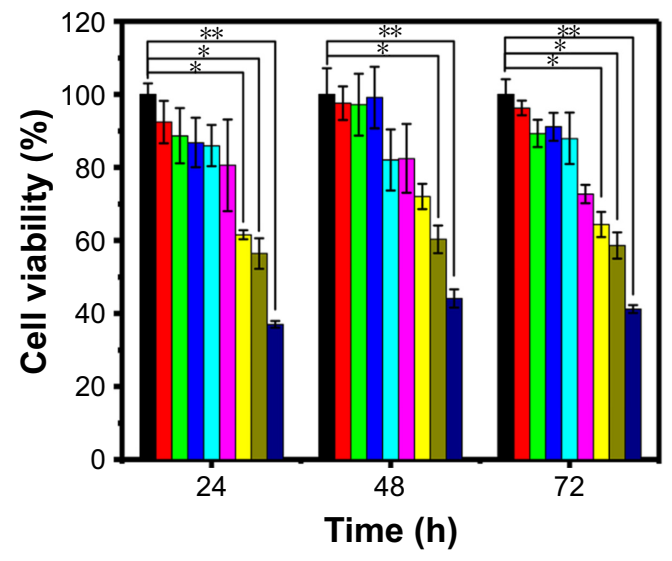

\begin{tabular}{|c|c|c|}
\hline Control & $0.001 \mu \mathrm{g} / \mathrm{mL}$ & $0.005 \mu \mathrm{g} / \mathrm{mL}$ \\
\hline $0.010 \mu \mathrm{g} / \mathrm{mL}$ & $0.050 \mu \mathrm{g} / \mathrm{mL}$ & $0.100 \mu \mathrm{g} / \mathrm{mL}$ \\
\hline $0.500 \mu \mathrm{g} / \mathrm{mL}$ & $1.000 \mu \mathrm{g} / \mathrm{mL}$ & $5.000 \mu \mathrm{g} / \mathrm{mL}$ \\
\hline
\end{tabular}

\begin{tabular}{|l|l|l|}
\hline $\mathrm{IC}_{50}$ for $24 \mathrm{~h}$ & $\mathrm{IC}_{50}$ for $48 \mathrm{~h}$ & $\mathrm{IC}_{50}$ for $72 \mathrm{~h}$ \\
\hline $1.48 \mu \mathrm{g} / \mathrm{mL}$ & $2.76 \mu \mathrm{g} / \mathrm{mL}$ & $2.54 \mu \mathrm{g} / \mathrm{mL}$ \\
\hline
\end{tabular}

Figure 7 The cell viability after incubation with different concentration of melatonin solution to find the optimal concentration for melatonin treatment, $n=6 ; * P<0.05$; $* * P<0.001$.

on MCF-7 cells were $1.48,2.76$ and $2.54 \mu \mathrm{g} / \mathrm{mL}$ for 24,48 and $72 \mathrm{~h}$, respectively. Therefore, the concentration of $1 \mu \mathrm{g} /$ $\mathrm{mL}$ was adopted for the following study. The viability data of MCF-7 cells subjected to mono-treatment (melatonin treatment or nano-thermotherapy) and melatonin combined with nano-thermotherapy based on Melatonin-MNPs are illustrated in Figure 8. Assessment of viable MCF-7 cells after various treatments showed mono-treatment such as melatonin and nano-thermotherapy could inhibit the proliferation of cells, and cell viability decreased with increased post-treatment time. When the bimodal treatment was applied on the cells, an even significantly greater decrease was noticed on the cell viability $(P<0.001)$, indicating a thermal enhancement effect of hyperthermia on melatonin.

\section{Discussion}

The studies about melatonin on human breast cancer can be traced back to $1981,{ }^{29}$ when Bartsch et al showed that compared with healthy people, Indian women with advanced breast cancer had diminished urinary levels of melatonin. Since then, great attention has been paid on the oncostatic effect on breast cancer and studies have revealed that melatonin-mediated circadian regulation, the metabolic and molecular signaling mechanisms may be involved in breast cancer growth. ${ }^{30}$ However, some significant inconsistence was also noticed on the results published on melatonin's effect on breast cancer cells. For instance, there exists magnitude difference in the effective concentration of melatonin on the antiproliferation effect on MCF-7 cells. It was proposed by David E. Blask that only at concentrations corresponding to the physiological range $\left(10^{-9} \mathrm{M}\right.$ and $\left.10^{-11} \mathrm{M}\right)$ could suppress the proliferation on MCF-7 cells while the pharmacological $\left(10^{-5} \mathrm{M}\right.$ and $\left.10^{-7} \mathrm{M}\right)$ and sub-physiological $\left(10^{-13} \mathrm{M}\right.$ and $10^{-15}$ $\mathrm{M})$ ranges have no such effect. ${ }^{10}$ However, their data were in contradiction with results from 2 independent studies recently published. By applying different concentrations of melatonin (0-100 nM), Nooshinfar et al could not find any significant difference in the viability index of MCF-7 cells, which is
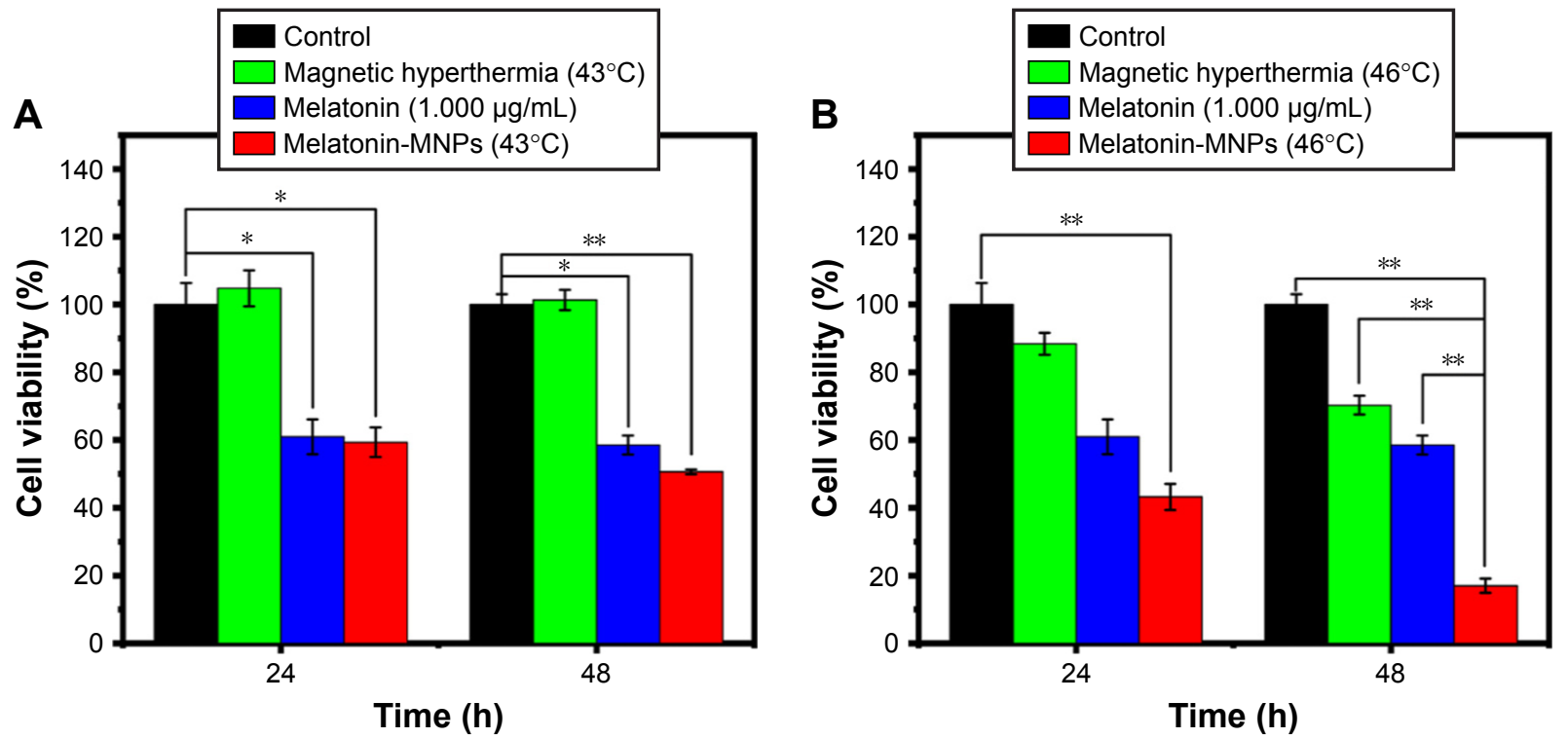

Figure 8 (A, B) In vitro cytotoxicity of hyperthermia therapy combined with melatonin treatment mediated by Melatonin-MNPs compared with the hyperthermia therapy or melatonin treatment alone, $\mathrm{n}=6$; $* \mathrm{P}<0.05 ; * * \mathrm{P}<0.00$ I.

Abbreviation: MNPs, magnetic nanocomposite particles. 
in accordance with our observation as shown in Figure $7 .^{31}$ Sabzichi et al conducted similar work and their result demonstrated that the $\mathrm{IC}_{50}$ value for melatonin on MCF-7 cells after $24 \mathrm{~h}$ co-incubation was $1.3 \pm 0.4 \mathrm{mM}$, which is almost $10^{6}$ higher than Blask and Hill's results. ${ }^{32}$ Such great difference in cell anti-proliferation effect of melatonin on $\mathrm{MCF}-7$ strongly suggests that systematic study of the basic data of melatonin on MCF-7 is still highly needed. Our study covers the concentration range of melatonin from $1 \mathrm{ng} / \mathrm{mL}$ to $1 \mu \mathrm{g} / \mathrm{mL}$ and we analyzed the $\mathrm{IC}_{50}$ values for 24,48 and $72 \mathrm{~h}$ continuously. While we did not observe noticeable change caused by melatonin in the very low concentration (physiological range), the $\mathrm{IC}_{50}$ values were not in the range of $\mathrm{mM}$ as proposed by $\mathrm{O}$ Molavi. Our findings may give some hints on the basic study of the antiproliferative effect of melatonin on MCF-7 cells.

Hyperthermia, the procedure of raising the temperature of tumor tissue, has been rapidly becoming a clinical reality for cancer treatment when combined with various established cancer treatments. ${ }^{33}$ Though the detailed biological basis of hyperthermia on cancer treatment is still under thorough investigation, it has been widely recognized that the possible effects may include protein or nucleic acid denaturation, alterations in the fluidity and stability of cellular membrane, induction to changes of the cytoskeletal organization or changes in tumor microcirculation and vasculature, etc. While conventional hyperthermia protocols could not discriminate the rumors and normal tissues nearby, the nonselective heating performance may lead to serious side effects. NP-based hyperthermia, or termed as nanothermotherapy, is highly expected to have great potential for the revolutionalization of current hyperthermia methods. ${ }^{34}$ Heat can be generated through the NPs infused within the tumor issue by absorbing the energy from an external source and thus realize the so-called "inside-out" hyperthermia, in a way to induce selective heating only within the tumor site while minimizing the adverse effect on nearby tissues. In the current study, based on the hyperthermic effects of MNPs subject to AMF, the effect of nano-thermotherapy on the $\mathrm{MCF}-7$ cells were investigated. Except for the unique feature associated with the heating protocol, our work has demonstrated the superior hyperthermic cytotoxicity by comparing the effect of heating treatment in response to the application of exogenous heating source (metal bath) with corresponding effect induced by magnetic nano-thermotherapy under the same thermal dose. It was revealed from our observations that for the same thermal dose, magnetic nano-thermotherapy can lead to a more remarkable decrease in cell vitality than the corresponding exogenous heating by metal bath. Such phenomenon can be understood by the cellular uptake of the NPs. Not like the exogenous heating mode, magnetic nanothermotherapy can rapidly form heating foci inside the cancer cells. Such "inside-out hyperthermia" may lead to more significant cytotoxic effect than the conventional "out-inside hyperthermia", as the cell membrane is normally regarded as a thermal insulator to protect the cells from heat injury.

In recent years, though much attention has been paid to the combination effect of hyperthermia and melatonin on cancer treatment, few studies have been carried out on the effect of nano-thermotherapy combined with melatonin. In the current study, for the first trial, heat mediator (magnetic NPs) and melatonin were co-incorporated with PLGA nanocomposite platform. The results presented here illustrate that the bimodal treatment, which combining the nano-thermotherapy and melatonin, will lead to more significant cell cytotoxicity compared with either single treatment. Melatonin can potentiate the cytotoxic response of MCF-7 cells exposed to hyperthermia, and such effect is dependent on the target temperature and recovery period. Most noticeable effect happened to higher temperature with long recovery period $\left(46^{\circ} \mathrm{C}, 48 \mathrm{~h}\right)$. The detailed underlying molecular mechanisms on the ability of melatonin to attenuate the cytotoxic response to hyperthermia should be necessarily elucidated by further analysis.

Another advantage of the Melatonin-MNPs is that the as-synthesized nanocomposite can be readily internalized within the MCF-7 cells by cellular uptake as indicated by Figure 5B, so as to achieve the intracellular drug treatment. Besides, as shown in Figure 4, the sustainable melatonin release can be controlled by heat-trigger. Melatonin can be released faster from the NP matrix upon stimulation by the magnetic heating. Two possible mechanisms may account for the promoted drug release from the PLGA matrix by heat. One is the facilitated effect on molecular diffusion of melatonin at higher temperature and another can be attributed to the phase transition of the polymer under higher temperature, that is, from crystalline phase to amorphous phase, so the drug can be easily released.

Since the early 2000s, research and development in the field of cancer nanotechnology has experienced an exponential growth and is currently progressing at a steady rate. ${ }^{35}$ One of the advantages of novel cancer nanotherapies over conventional small-molecule treatment is reflected in the enhanced drug uptake and selective intracellular accumulation in cancer cells based on both passive and active targeting, thus alleviating unwanted toxicity to normal tissues. The passive targeting, based on enhanced permeability and retention (EPR) effect, is caused by the leaky blood vessels 
within tumors with trans-vascular endothelium gaps ranging between 100 and 2,000 nm, which depends on the tumor type. The particle size of as-synthesized Melatonin-MNPs is about $250 \mathrm{~nm}$, which definitely meets the requirement of EPR effect. More importantly, the nano-sized MelatoninMNPs have great potential to be uptaken by MCF-7 cancer cells through various mechanisms, including endocytosis in a way to effectively avoid the drug-resistance mechanisms to conventional small-molecule drug, such as multidrug resistance efflux transporters, hence enhancing cellular accumulation of the cytotoxic agents and also inducing the so-called intracellular drug treatment. Particle size plays a very important role in the fate of cellular uptake for the NPs. Previous results from in vitro investigation, theoretical prediction as well as computer simulation are in accordance with each other and it is well established that particles with size ranging from 100 to $200 \mathrm{~nm}$ may have the best effects for cellular uptake. For our case, the particle size is about $250 \mathrm{~nm}$, very near to the optimal size range.

Except for passive targeting, active targeting, also called ligand-mediated targeting, which utilizes a high-affinity targeting ligand for selective recognition through a specific receptor or antigen overexpressed on the surface of the cancer cells, is also an important and effective mechanism for the specific retention and uptake by the cancer cells. For this purpose, proper surface functionalities should be performed by coating with the targeting ligand enabling specific binding to a receptor or antigen overexpressed on the cell surface of malignant cells. It has been fully acknowledged that monoclonal antibodies demonstrate excellent tumor-binding specificity. However, the high cost, low availability and the required difficulties in incubation limit the application of monoclonal antibodies as a targeting agent. Therefore, it would be significant to develop cheap and easily acquired molecules as targeting moiety for potential clinical application. It has been well documented that melatonin signals through activation of at least 2 high-affinity G-protein coupled receptors, the MT1 and MT2. ${ }^{36}$ The oncostatic actions of melatonin appears to be mediated primarily through the activation of MT1 melatonin receptors. In our study, by comparing the efficiency in cellular uptake of NPs with and without melatonin loading, it thus can be obviously noticed that melatonin can promote cellular uptake of the NPs by the MCF-7 cells, which overexpress GLUTs (Figure 1). Our findings can strongly indicate that melatonin can effectively enhance the specificity of the nanodevices to the tumor cells by enhancing cellular uptake and accumulation.

\section{Conclusion}

In summary, the present study gave the first trial to fabricate the precisely engineered melatonin-loaded multifunctional NPs and to demonstrate the potential in cancer target multimodality treatment. Unique properties of melatonin on anti-cancer treatment, including antiproliferation effect on MCF-7 cells, active targeting to cancer cells based on facilitated transport by GLUT1 overexpressed on cell membrane, as well as the potentiated effect on nano-thermotherapy can by fully exploited within the multifunctional nanoplatform. Our findings may give new insight on the potential application of melatonin in cancer nanotechnology.

\section{Acknowledgment}

This study was supported by grants of the National Natural Science Foundation of China (No 81671829).

\section{Author contributions}

All authors contributed toward data analysis, drafting and critically revising the paper, gave final approval of the version to be published, and agree to be accountable for all aspects of the work.

\section{Disclosure}

The authors report no conflicts of interest in this work.

\section{References}

1. Mediavilla MD, Sanchez-Barcelo EJ, Tan DX, Manchester L, Reiter RJ. Basic mechanisms involved in the anti-cancer effects of melatonin. Curr Med Chem. 2010;17(36):4462-4481.

2. Lerner $\mathrm{AB}$, Case JD, Takahashi $\mathrm{Y}$, et al. Isolation of melatonin, the pineal gland factor that lightens melanocytes. J Am Chem Soc. 1958; 80(10):2587-2587.

3. Galano A, Tan DX, Reiter RJ. Melatonin as a natural ally against oxidative stress: a physicochemical examination. J Pineal Res. 2011;51(1): $1-16$.

4. Larson ET, Winberg S, Mayer I, Lepage O, Summers CH, Øverli Ø. Social stress affects circulating melatonin levels in rainbow trout. Gen Comp Endocrinol. 2004;136(3):322-327.

5. López-Muñoz F, Boya J, Marín F, Calvo JL. Scientific research on the pineal gland and melatonin: a bibliometric study for the period 1966-1994. J Pineal Res. 1996;20(3):115-124.

6. López-Muñoz F, Povedano FJ, Álamo C. Bibliometric study of scientific research on melatonin during the last 25 years. Melatonin, neuroprotective agents and antidepressant therapy. Springer India. 2016:25-42.

7. Cajochen C, Kräuchi K, Wirz-Justice A. Role of melatonin in the regulation of human circadian rhythms and sleep. J Neuroendocrinol. 2003; 15(4):432-437.

8. Blask DE. Melatonin, sleep disturbance and cancer risk. Sleep Med Rev. 2009;13(4):257-264.

9. Leon J, Acuña-Castroviejo D, Escames G, Tan DX, Reiter RJ. Melatonin mitigates mitochondrial malfunction. J Pineal Res. 2005;38(1):1-9.

10. Hill SM, Blask DE. Effects of the pineal hormone melatonin on the proliferation and morphological characteristics of human breast cancer cells (MCF-7) in culture. Cancer Res. 1988;48(21):6121-6126. 
11. Sánchez-Barceló EJ, Cos S, Mediavilla D, Martínez-Campa C, González A, Alonso-González C. Melatonin-estrogen interactions in breast cancer. J Pineal Res. 2005;38(4):217-222.

12. Jung B, Ahmad N. Melatonin in cancer management: progress and promise. Cancer Res. 2006;66(20):9789-9793.

13. Kubatka P, Bojková B, Mciková-Kalická K, et al. Effects of tamoxifen and melatonin on mammary gland cancer induced by N-methyl-Nnitrosourea and by 7, 12-dimethylbenz (a) anthracene, respectively, in female Sprague-Dawley rats. Folia Biol (Praha). 2001;47(1):5-10.

14. Casado-Zapico S, Rodriguez-Blanco J, García-Santos G, et al. Synergistic antitumor effect of melatonin with several chemotherapeutic drugs on human Ewing sarcoma cancer cells: potentiation of the extrinsic apoptotic pathway. J Pineal Res. 2010;48(1):72-80.

15. Matsuzuka T, Sakamoto N, Ozawa M, Ushitani A, Hirabayashi M, Kanai Y. Alleviation of maternal hyperthermia-induced early embryonic death by administration of melatonin to mice. J Pineal Res. 2005;39(3):217-223.

16. Ferlay J, Héry C, Autier P, Sankaranarayanan R. Global burden of breast cancer. Breast Cancer Epidemiol. 2010:1-19.

17. Kelland L. The resurgence of platinum-based cancer chemotherapy. Nat Rev Cancer. 2007;7(8):573-584.

18. Hamdy FC, Donovan JL, Lane JA, et al. 10-year outcomes after monitoring, surgery, or radiotherapy for localized prostate cancer. $N$ Engl J Med. 2016;375:1415-1424.

19. Espinosa A, Di-Corato R, Kolosnjaj-Tabi J, Flaud P, Pellegrino T, Wilhelm C. Duality of iron oxide nanoparticles in cancer therapy: amplification of heating efficiency by magnetic hyperthermia and photothermal bimodal treatmen. ACS Nano. 2016;10(2):2436-2446.

20. Rezaee M, Oskuee RK, Nassirli H, Malaekeh-Nikouei B. Progress in the development of lipopolyplexes as efficient non-viral gene delivery systems. J Control Release. 2016;236:1-14.

21. Maccalli C, De Maria R. Cancer stem cells: perspectives for therapeutic targeting. Cancer Immunol Immunother. 2015;64(1):91-97.

22. Inoue Y, Iwata T, Okugawa Y, et al. Prognostic significance of a systemic inflammatory response in patients undergoing multimodality therapy for advanced colorectal cancer. Oncology. 2013;84(2):100-107.

23. Dimou F, Sineshaw H, Parmar AD, Tamirisa NP, Jemal A, Riall TS. Trends in receipt and timing of multimodality therapy in early-stage pancreatic cancer. J Gastrointest Surg. 2016;20(1):93-103.
24. Beik J, Abed Z, Ghoreishi FS, et al. Nanotechnology in hyperthermia cancer therapy: from fundamental principles to advanced applications. J Control Release. 2016;235:205-221.

25. Bertrand N, Wu J, Xu X, Kamaly N, Farokhzad OC. Cancer nanotechnology: the impact of passive and active targeting in the era of modern cancer biology. Adv Drug Deliv Rev. 2014;66:2-25.

26. Sun S, Zeng H, Robinson DB, et al. Monodisperse MFe2O4 ( $\mathrm{M}=\mathrm{Fe}$, Co, Mn) nanoparticles. J Am Chem Soc. 2004;126(1):273-279.

27. Yuan J, Liu J, Song Q, et al. Photoinduced mild hyperthermia and synergistic chemotherapy by one-pot-synthesized docetaxel-loaded poly (lactic-co-glycolic acid)/polypyrrole nanocomposites. ACS Appl Mater Interfaces. 2016;8(37):24445-24454.

28. Wang H, Li L, Wang P, Wang X, Zhang K, Liu Q. Comparison of photodynamic treatment produced cell damage between human breast cancer cell MCF-7 and its multidrug resistance cell. Photodiagnosis Photodyn Ther. 2016;16:1-8.

29. Bartsch C, Bartsch H, Jain AK, Laumas KR, Wetterberg L. Urinary melatonin levels in human breast cancer patients. J Neural Transm. 1981; 52(4):281-294.

30. Hill SM, Belancio VP, Dauchy RT, et al. Melatonin: an inhibitor of breast cancer. Endocr Relat Cancer. 2015;22(3):R183-R204.

31. Nooshinfar E, Bashash D, Safaroghli-Azar A, et al. Melatonin promotes ATO-induced apoptosis in MCF-7 cells: proposing novel therapeutic potential for breast cancer. Biomed Pharmacother. 2016;83: 456-465.

32. Sabzichi M, Samadi N, Mohammadian J, Hamishehkar H, Akbarzadeh M, Molavi O. Sustained release of melatonin: a novel approach in elevating efficacy of tamoxifen in breast cancer treatment. Colloids Surf B Biointerfaces. 2016;145:64-71.

33. Perigo EA, Hemery G, Sandre O, et al. Fundamentals and advances in magnetic hyperthermia. Appl Phys Rev. 2015;2:1-35.

34. Kumar CSSR, Mohammad F. Magnetic nanomaterials for hyperthermiabased therapy and controlled drug delivery. Adv Drug Deliv Rev. 2011 63(9):789-808.

35. Ferrari M. Cancer nanotechnology: opportunities and challenges. Nat Rev Cancer. 2005;5(3):161-171.

36. Dubocovich ML, Markowska M. Functional MT1 and MT2 melatonin receptors in mammals. Endocrine. 2005;27(2):101-110.
International Journal of Nanomedicine

\section{Publish your work in this journal}

The International Journal of Nanomedicine is an international, peerreviewed journal focusing on the application of nanotechnology in diagnostics, therapeutics, and drug delivery systems throughout the biomedical field. This journal is indexed on PubMed Central, MedLine, CAS, SciSearch $®$, Current Contents $\AA /$ Clinical Medicine,

\section{Dovepress}

Journal Citation Reports/Science Edition, EMBase, Scopus and the Elsevier Bibliographic databases. The manuscript management system is completely online and includes a very quick and fair peer-review system, which is all easy to use. Visit http://www.dovepress.com/ testimonials.php to read real quotes from published authors. 